\title{
Imaging receptor for advanced glycation end product expression in mouse model of hind limb ischemia
}

Yared Tekabe ${ }^{1}$, Maria Kollaros ${ }^{1}$, Chong Li ${ }^{1}$, Geping Zhang ${ }^{2}$, Ann Marie Schmidt ${ }^{3}$ and Lynne Johnson ${ }^{1 *}$

\begin{abstract}
Background: The purpose of this study is to image the effect of diabetes on expression of receptor for advanced glycation endproducts (RAGE) in limb ischemia in live animals.

Methods: Male wild-type C57BL/6 mice were either made diabetic or left as control. Two months later, diabetic and non-diabetic mice underwent left femoral artery ligation. The right leg served as lesion control. Five days later, mice were injected with $15.1 \pm 4.4 \mathrm{MBq}{ }^{99 \mathrm{~m} T c-a n t i-R A G E ~} \mathrm{~F}\left(\mathrm{ab}^{\prime}\right)_{2}$ and 4 to $5 \mathrm{~h}$ later (blood pool clearance) underwent SPECT/CT imaging. At the completion of imaging, mice were euthanized, hind limbs counted and sectioned, and scans reconstructed. Regions of interest were drawn on serial transverse sections comprising the hind limbs and activity in millicuries summed and divided by the injected dose (ID). Quantitative histology was performed for RAGE staining and angiogenesis.

Results: Uptake of ${ }^{99 \mathrm{~m}} \mathrm{Tc}$-anti-RAGE $\mathrm{F}\left(\mathrm{ab} \mathrm{b}^{\prime}\right)_{2}$ as $\% \mathrm{ID} \times 10^{-3}$ was higher in the left (ischemic) limbs for the diabetic mice $(n=8)$ compared to non-diabetic mice $(n=8)(1.20 \pm 0.44 \%$ vs. $0.49 \pm 0.40 \% ; P=0.0007)$ and corresponded to less angiogenesis in the diabetic mice. Uptake was also higher in the right limbs of diabetic compared to nondiabetic animals ( $0.82 \pm 0.33 \%$ vs. $0.40 \pm 0.14 \% ; P=0.0004)$.
\end{abstract}

Conclusions: These data show the feasibility of imaging and quantifying the effect of diabetes on RAGE expression in limb ischemia.

Keywords: Limb ischemia, Diabetes, RAGE, Molecular imaging, Radionuclides

\section{Background}

Peripheral artery disease (PAD) is a common condition producing symptomatic ischemic leg pain with exertion (claudication) and in diabetics can be a particularly malignant disease leading to rest pain and gangrene requiring amputation. There are currently no effective drug therapies for symptomatic PAD, leaving surgical revascularization and interventional catheter-based approaches. There is a wealth of published data from experimental studies and a few clinical studies that provide evidence to support the central role for receptor for advanced glycation endproducts (RAGE) in the development and progression of PAD in atherosclerosis and diabetes.

\footnotetext{
* Correspondence: lj2129@columbia.edu

'Department of Medicine, Columbia University Medical Center, 622 West 168th St, PH 10 room 203, New York, NY 10032, USA

Full list of author information is available at the end of the article
}

RAGE is a $35 \mathrm{kDa}$ polypeptide of the immunoglobulin superfamily that is a multiligand receptor shown to be an important mediator of inflammation in a variety of conditions including atherosclerosis and the complications of diabetes [1-7]. RAGE is constitutively expressed at low levels on smooth muscle cells and endothelial cells in the vascular endothelium [3]. Increased expression of RAGE in the vascular wall occurs in response to a number of stimuli including hyperlipidemia and hyperglycemia [3-6]. In the non-diabetic limb, in response to tissue hypoxia, via the hypoxia-inducible factor-1 alpha (HIF-1a) pathway, vascular endothelial growth factor (VEGF) is released locally and stimulates angiogenesis through multiple mechanisms that include increased proliferation and decreased apoptosis of endothelial cells and chemoattraction of monocytes into the ischemic tissue $[8,9]$. In diabetes, this normally adaptive response to 
hypoxia is blunted. RAGE has been shown to have a major mechanistic role in this maladaptive response by reducing VEGF mRNA and by inducing a defect in signal transduction resulting in fewer monocytes in the tissue to stimulate angiogenesis [10-12]. Experimental studies suppressing RAGE ligands have shown improvement in angiogenic response to limb ischemia [13,14].

We have previously shown that molecular imaging using a radionuclide probe targeting $\alpha \nu \beta 3$ expression during angiogenesis can detect the effect of diabetes to suppress angiogenesis in mouse models of hind limb ischemia [15]. We have developed a radiolabeled murine monoclonal antibody targeting RAGE for in vivo imaging of RAGE expression and have shown focal uptake of this probe in atheroma in apolipoprotein E-deficient $\left(\mathrm{apoE}^{-/-}\right)$mice both with and without diabetes [16]. In this current study, we extend our previous work to investigate the hypothesis that RAGE-directed molecular imaging can detect the effect of diabetes on RAGE expression in a murine model of hind limb ischemia.

\section{Methods}

All animal experiments were performed in accordance with the approval of the Institutional Animal Care and Use Committee of Columbia University. Male wild-type (WT) C57BL/6 mice $(n=20)$ were obtained (Jackson Laboratories, Bar Harbor, ME, USA). Diabetic mice $(n=8)$ and non-diabetic mice $(n=8)$ were injected with radiolabeled anti-RAGE $\mathrm{F}\left(\mathrm{ab}^{\prime}\right)_{2}$. Probe control non-diabetic mice $(n=4)$ were injected with non-immune $\operatorname{IgG~F}\left(\mathrm{ab}^{\prime}\right)_{2}$.

\section{Induction of diabetes}

At 6 weeks of age, mice were treated with streptozotocin (STZ; Sigma-Aldrich Corporation, St. Louis, MO, USA). Animals were injected with five consecutive daily doses of STZ dissolved in citrate buffer ( $55 \mathrm{mg} / \mathrm{kg}, \mathrm{pH} 4.5$ ) via the intraperitoneal route. One week after the first dose, blood glucose levels were assessed using a glucometer. The criterion of two consecutive glucose levels $>250 \mathrm{mg} / \mathrm{dL}$ was used to indicate diabetes. If glucose levels were $<250 \mathrm{mg} / \mathrm{dL}$, then the mice received two additional doses of STZ. Both diabetic and non-diabetic mice were followed for 2 months to allow the diabetes to stabilize before femoral artery ligation.

\section{Femoral artery ligation}

The hair on the abdominal wall and pelvis and the upper legs was shaved using an electronic shaver after the mouse was under anesthesia with $4 \%$ isoflurane induction and $1 \%$ maintenance. The skin was prepped using povidone-iodine (5\%) followed by three alcohol preps. A skin incision was made on the upper thigh of the mouse. The inguinal ligament and the upper half of the femoral artery are exposed in both legs. On the left leg, the femoral artery was ligated with two sterile $8 / 0$ nonabsorbable silk sutures below the inguinal ligament proximally and just above the bifurcation into the superficial and deep femoral arteries distally. The vascular bundle on the right leg was isolated without further intervention. The skin incision was closed with sterile 5/0 nylon suture.

\section{Preparation of radiotracer}

Monoclonal anti-RAGE antibody was developed as previously described [16]. For ${ }^{99 \mathrm{~m}}$ Tc labeling, the antibody was fragmented into $\mathrm{F}\left(\mathrm{ab}^{\prime}\right)_{2}$ using a pepsin digestion kit (Pierce, Rockford, IL, USA). Approximately $1 \mathrm{mg}$ of the $\mathrm{F}\left(\mathrm{ab}^{\prime}\right)_{2}$ was conjugated with $5 \mathrm{M}$ excess of diethylene triamine pentaacetic acid (DTPA; Sigma). The reaction mixture was incubated at room temperature for $30 \mathrm{~min}$ followed by overnight dialysis at $4^{\circ} \mathrm{C}$ in phosphatebuffered saline (PBS) $\left(0.15 \mathrm{M} \mathrm{NaCl}, 0.05 \mathrm{M} \mathrm{NaHCO}_{3}\right.$, $\mathrm{pH}$ 7.6). To 50 to $100 \mu \mathrm{g}$ of anti-RAGE $\mathrm{F}\left(\mathrm{ab}^{\prime}\right)_{2}, 50 \mu \mathrm{g}$ of $\mathrm{SnCl}_{2}$ in $0.1 \mathrm{~N} \mathrm{HCl}$ (flushed in $\mathrm{N}_{2}$ gas for $15 \mathrm{~min}$ ) and 30 to $50 \mathrm{mCi}{ }^{99 \mathrm{~m}} \mathrm{Tc}$ were added and incubated at room temperature for $45 \mathrm{~min}$. The ${ }^{99 \mathrm{~m}} \mathrm{Tc}$-labeled antibody fragments were separated from free ${ }^{99 \mathrm{~m}} \mathrm{Tc}$ using a PD-10 column pre-equilibrated with $0.1 \mathrm{M}$ PBS ( $\mathrm{pH}$ 7.4). The mean radiopurity was $97 \pm 0.5 \%$ by instant thin-layer chromatography. Control non-specific mouse IgG $\mathrm{F}\left(\mathrm{ab}^{\prime}\right)_{2}$ was similarly conjugated with DTPA for ${ }^{99 \mathrm{~m}} \mathrm{Tc}$ labeling as described above.

\section{In vivo imaging}

Five days after femoral artery ligation, each mouse was anesthetized with isofluorane ( $4 \%$ to induce, $1 \%$ to maintain) for placement of a jugular vein catheter (Braintree Scientific, Braintree, MA, USA) and was injected with $0.41 \pm 0.12 \mathrm{mCi}{ }^{99 \mathrm{~m}} \mathrm{Tc}$-anti-RAGE $\mathrm{F}\left(\mathrm{ab}^{\prime}\right)_{2}$ or control nonspecific mouse IgG $\mathrm{F}\left(\mathrm{ab}^{\prime}\right)_{2}$ and 4 to $5 \mathrm{~h}$ later (blood pool clearance) underwent single-photon emission computed tomography/computed tomography (SPECT/CT) imaging on nanoSPECT/CT (Bioscan, Washington, DC, USA).

A topogram (sequence of 2D side view X-ray projections) was used to determine the axial scan range for SPECT and CT imaging. CT images were acquired with an integrated CT scanner using an X-ray tube at $45 \mathrm{kVp}$ and an exposure time of $1,000 \mathrm{~ms}$ per view. Following $\mathrm{CT}$ acquisition, helical SPECT scans were acquired using dual-headed detectors, each outfitted with nine pinhole apertures. Each pinhole has a diameter of $1.4 \mathrm{~mm}$ with each collimator providing a transaxial field-of-view (FOV) of $30 \mathrm{~mm}$ and an axial FOV of $16 \mathrm{~mm}$, extendable through helical scanning to $270 \mathrm{~mm}$. SPECT data were acquired with the following parameters: step and shoot rotation, $30^{\circ}$ step in $360^{\circ}$ rotation using 24 projections, $60 \mathrm{~s}$ per projection, $256 \times 256$ frame size with $1.0-\mathrm{mm}$ pixels, and $140 \mathrm{keV}$ with $10 \%$ energy window. The obtained projection data were reconstructed by ordered subsets 
expectation maximization algorithm with the subset and iteration number set to 16 and 8, respectively, and a voxel size of $300 \mu \mathrm{m}$ and SPECT and CT datasets fused.

At the completion of in vivo imaging, mice were euthanized by an intraperitoneal injection of pentobarbital $(100 \mathrm{mg} / \mathrm{kg})$.

\section{Image analyses}

The scans were reconstructed and processed using InVivoScope software (Invicro, Boston, MA, USA). On serial 5-voxel-thick transverse sections from below hip joints to distal hind limbs, regions of interest were drawn and activity in $\mathrm{mCi}$ summed for each limb and subsequently divided by the injected dose (ID).

\section{Gamma well counting}

The anterior tibialis muscles were dissected and weighed, and the radioactivity was determined in a gamma well counter (Wallac Wizard 1470, PerkinElmer, Waltham, MA, USA) and expressed as the percentage of injected dose per gram $(\% \mathrm{ID} / \mathrm{g})$ of tissue. The radiotracer activity in the samples was corrected for background, decay time, and tissue weight.

\section{Histopathology}

Three sets of explanted tibialis anterior muscles per group were fixed in $10 \%$ formalin for $48 \mathrm{~h}$. Three serial sections $(5 \mu \mathrm{m}$ thick) per experiment from paraffinembedded blocks were processed for hematoxylin and eosin (H\&E) for morphological evaluation and immunohistochemical analysis.

Serial sections were deparaffinized and rehydrated followed by quenching of endogenous peroxidase activity with $0.3 \%$ hydrogen peroxide. Slides were then incubated overnight with monoclonal anti-RAGE antibody $(50 \mu \mathrm{g} / \mathrm{ml})$. Slides were incubated for $30 \mathrm{~min}$ with biotinylated secondary antibody. To identify capillary sprouting, staining was performed with biotinylated Griffonia (Bandeiraea) simplicifolia isolectin I (1:50; Vector Laboratories, Burlingame, CA, USA). Sections were treated for $30 \mathrm{~min}$ with VECTASTAIN ABC reagent (Vector Laboratories). Color reaction was visualized with $3^{\prime}, 3^{\prime}$-diaminobenzidine (DAB substrate kit, Dako, Mississauga, Ontario, Canada) and counterstained with Gill's hematoxylin solution. All brown staining areas were counted for each of the three sections for both the left and right anterior tibialis muscles for each experiment, and averaged RAGE and lectin staining were quantified as area staining positive for the brown chromogen per $100 \times$ field.

Images were captured using a digital camera mounted on a Nikon microscope (Nikon Co., Tokyo, Japan) and analyzed using Image-Pro Plus software (Media Cybernetics Inc., Bethesda, MD, USA).

\section{Immunofluorescence}

Dual fluorescent confocal microscopy studies were performed to identify the cell source of RAGE staining. Muscle sections ( $5 \mu \mathrm{m}$ thick) were deparaffinized in xylene and incubated with monoclonal mouse anti-RAGE F(ab') $(50 \mu \mathrm{g} / \mathrm{ml}$; Texas Red) and co-stained with endothelial cells (FVIII, 1:200; fluorescein isothiocyanate), macrophages (Mac-3, 1:50; fluorescein isothiocyanate), and myocytes (anti-sarcomeric actin, 1:50; fluorescein isothiocyanate). The images were examined using a confocal fluorescence microscope (Nikon) and SPOT imaging software (Diagnostic Instruments, Inc., Sterling Heights, MI, USA).

\section{Statistical analysis}

Continuous variables were expressed as mean \pm standard deviation. Normality was assessed using the SharpiroWilk $W$ test. Equality of variances was assessed using Levene's test. Comparisons between groups were made using paired two-tailed Student's $t$ test or the MannWhitney $U$ test, as appropriate with $P<0.05$ denoting significance. Correlation was assessed using the Pearson product-moment correlation coefficient. Statistical analyses were performed using STATA 10.1 (StataCorp, College Station, TX, USA).

\section{Results}

\section{Scan analysis}

Summed uptake of the probe on coronal slices from SPECT/CT scans following injection of ${ }^{99 \mathrm{~m}} \mathrm{Tc}$-anti-RAGE $\left.\mathrm{F}(\mathrm{ab})_{2}\right)_{2}$ days after left femoral artery ligation showed greater uptake of the tracer in the left (ischemic) limbs of diabetic mice compared to the probe uptake in the ischemic limbs of non-diabetic mice injected with ${ }^{99 \mathrm{~m}} \mathrm{Tc}$-antiRAGE $F\left(a b^{\prime}\right)_{2}$ or in the ischemic limb of mice injected with non-specific IgG $\mathrm{F}\left(\mathrm{ab}^{\prime}\right)_{2}$ (control probe) (Figure 1A). The quantitative tracer uptake as \%ID in the diabetic left (ischemic) $\operatorname{limb}\left(1.2 \pm 0.44 \times 10^{-3}\right)$ was significantly higher than the uptake in the non-diabetic left limb $(0.49 \pm$ $0.40 \times 10^{-3} ; P=0.0007$ ) (Figure 1B). Tracer uptake in the diabetic right (non-ischemic) limb $\left(0.82 \pm 0.33 \times 10^{-3}\right)$ was also significantly higher than the uptake in the nondiabetic right limb $\left(0.40 \pm 0.14 \times 10^{-3} ; P=0.0004\right)$.

\section{Ex vivo gamma counting}

The higher uptake of ${ }^{99 \mathrm{~m}} \mathrm{Tc}$-anti-RAGE $\mathrm{F}\left(\mathrm{ab}^{\prime}\right)_{2}$ in the diabetic left (ischemic) limbs was confirmed by ex vivo gamma well counting (Figure 2). The mean tracer uptake in the diabetic left limbs as \% ID/g (0.046 \pm 0.017$)$ was significantly higher than the uptake in the nondiabetic left limbs $(0.019 \pm 0.012 ; P=0.02)$ or limbs of mice injected with non-specific control $\operatorname{IgG} \mathrm{F}\left(\mathrm{ab}^{\prime}\right)_{2}$ $(0.005 \pm 0.0007 ; P=0004)$ (Figure $2 \mathrm{~A})$. The mean count ratio for left to right ( $\mathrm{L} / \mathrm{R}$ ratio) hind limbs for diabetic 

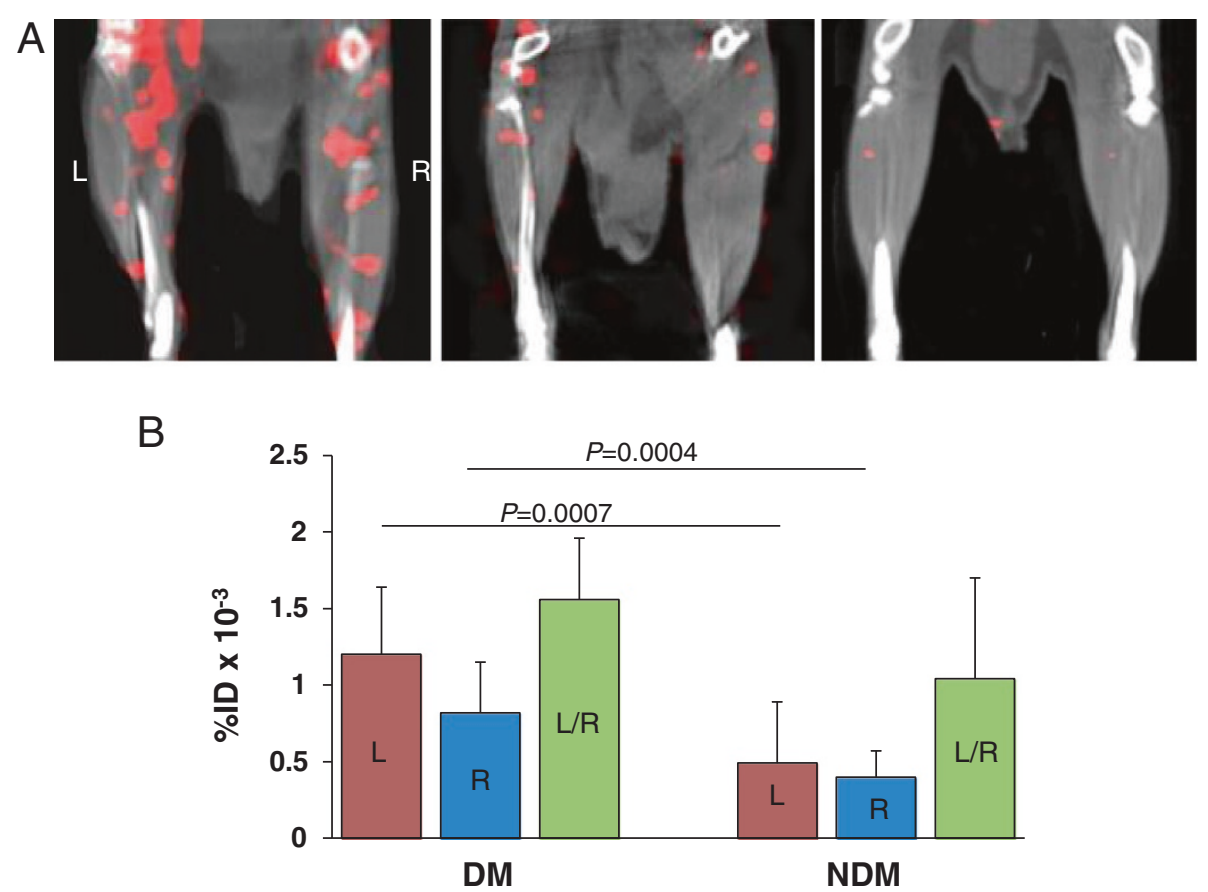

Figure 1 Scan results. (A) Representative coronal slices from SPECT/CT scans following injection of ${ }^{99 \mathrm{~m} T \text { T }-a n t i-R A G E ~ F(a b ') ~} 5$ days after left FAL for a WT diabetic mouse (left), WT non-diabetic mouse (center), and WT non-diabetic mouse injected with non-specific mouse lgG F(ab') 2 (right). (B) Bar graph shows quantitative RAGE uptake from scans in hind limbs for WT diabetic (left set of bars) and WT non-diabetic (right side set of bars) 5 days after FAL. Each bar represents average \pm SD. DM, diabetes mellitus; NDM, non-diabetes mellitus; FAL, femoral artery ligation; WT, wild type.

mice $(3.29 \pm 0.72)$ was also significantly higher than that for non-diabetic $(1.66 \pm 0.65 ; P=0.01)$ or mice injected with control non-specific $\operatorname{IgG} \mathrm{F}\left(\mathrm{ab}^{\prime}\right)_{2}(0.95 \pm 0.15 ; P=$ 0.001) (Figure 2B).

\section{Histopathology}

Immunohistopathology supported the scan findings. Examples of anterior tibialis muscle tissue sections stained for $H \& E$ and RAGE are shown in Figure 3. The average RAGE staining, determined as percent area staining positive for the brown chromogen per $100 \times$ field, for the diabetic left limbs $(21.3 \pm 6.2 \%)$ was significantly greater than that for the contralateral right limb $(5.6 \pm 4.3 \% ; P=$ $0.02)$ or non-diabetic left limbs (7.6 $\pm 5.6 \% ; P=0.04)$. Dual fluorescent staining identified RAGE co-localization predominantly with myocytes within the ischemic muscle (Figure 4).

Serial sections were also stained for capillary sprouting (biotinylated Griffonia (Bandeiraea) simplicifolia isolectin I). Lectin staining for the non-diabetic left limbs (1.25 \pm $0.36 \%)$ was significantly higher than that for the diabetic left limbs $(0.61 \pm 0.13 \% ; P=0.01)$ (Figure 5).
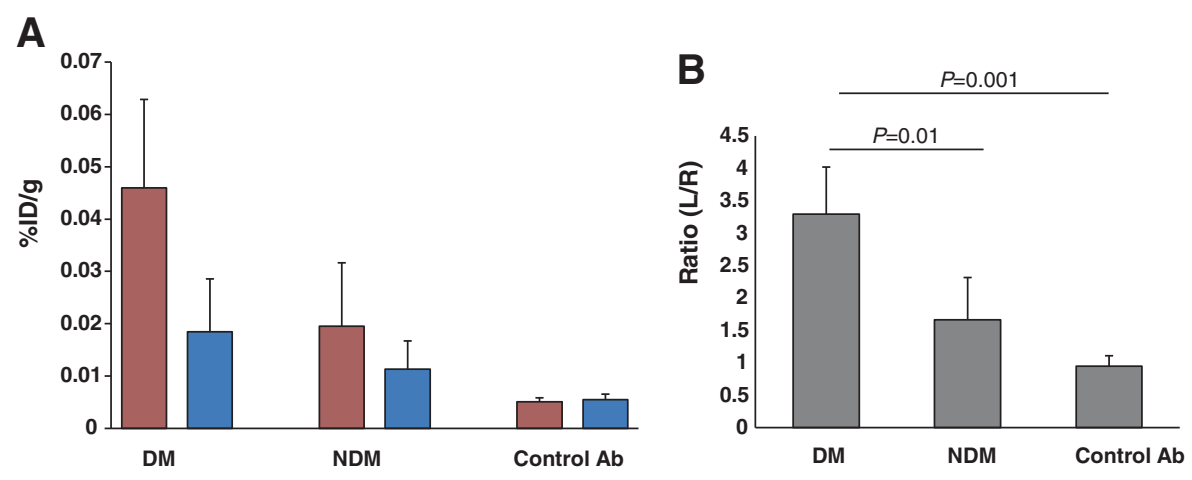

Figure 2 Ex vivo well counting for both hind limbs. (A) Bars represent values for \%lD/g. The red bars represent left (ischemic) hind limbs and the blue bars represent the right hind limbs. (B) Bars represent values for the ratios of left/right (L/R) limbs. 


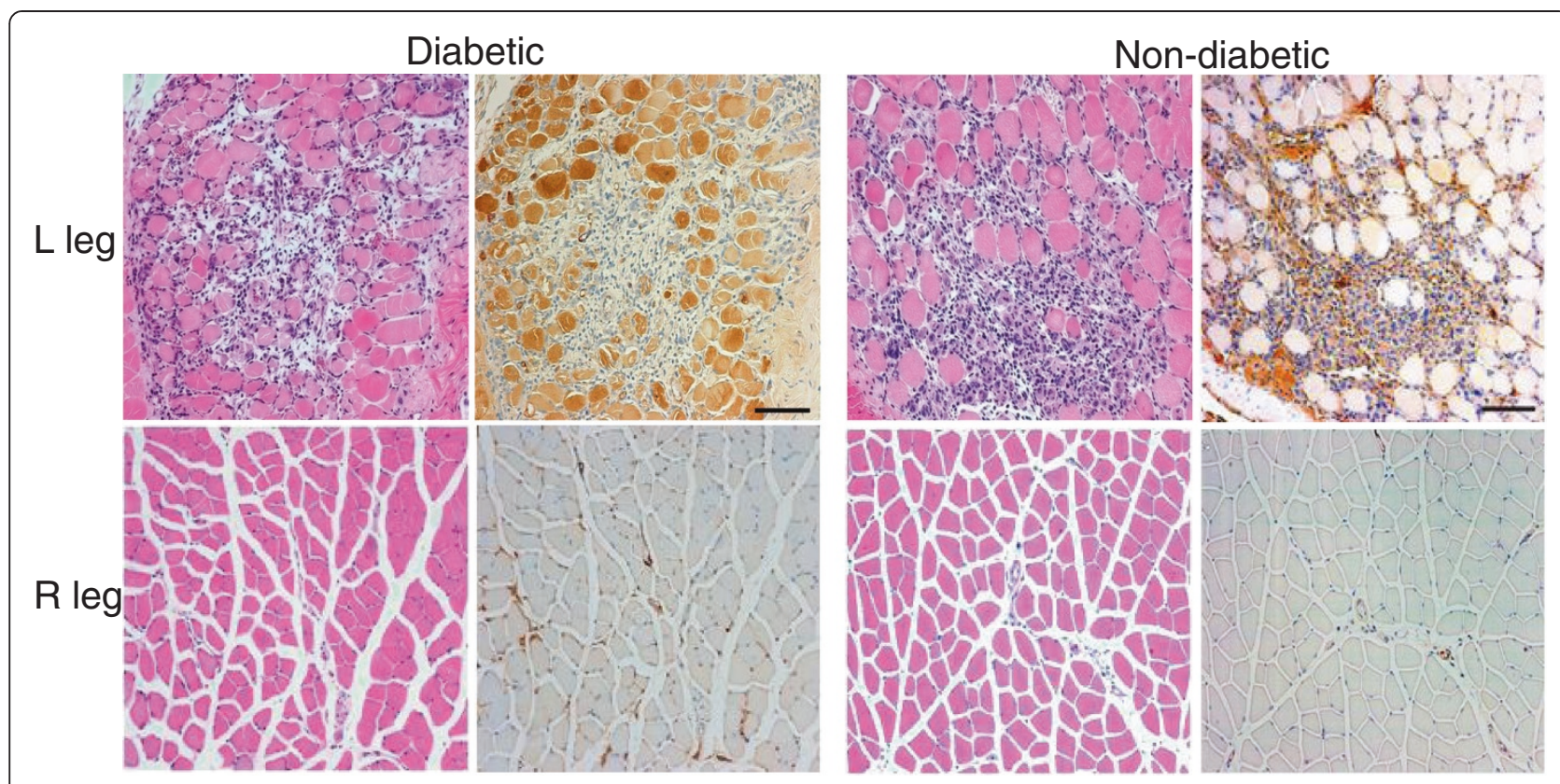

Figure 3 Histological findings. Serial sections from ischemic (L) diabetic and non-diabetic limbs. H\&E staining is shown on the left and RAGE staining (brown) on the right for each set of images. Scale bar $=100 \mu \mathrm{m}$.
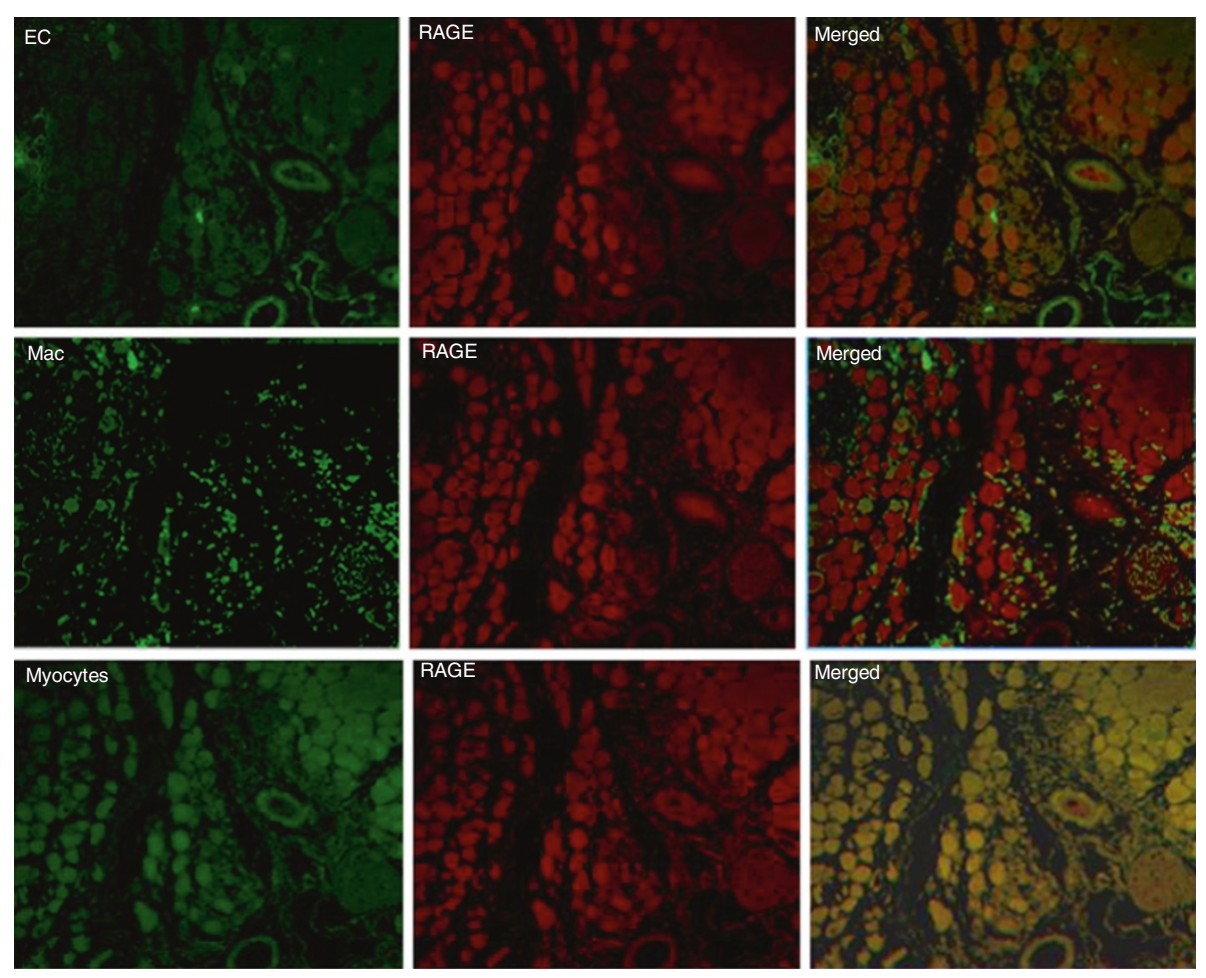

Figure 4 Dual immunofluorescent staining for cells expressing RAGE in ischemic limb sections. Sites of RAGE expression were shown to be mainly myocytes based on co-localization of RAGE (Texas Red) with anti-sarcomeric actin (green, fluorescein isothiocyanate) in the merged image. Co-localization of RAGE with macrophages (Mac-3, fluorescein isothiocyanate) was also seen in the merged image. Areas in yellow represent co-localization. EC, endothelial cells; Mac, macrophages. 


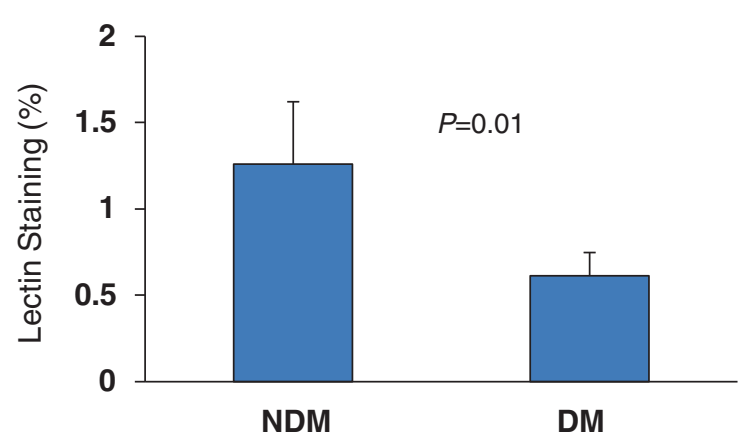

Non-diabetic

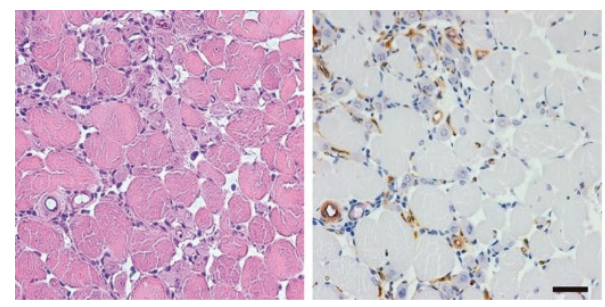

Diabetic

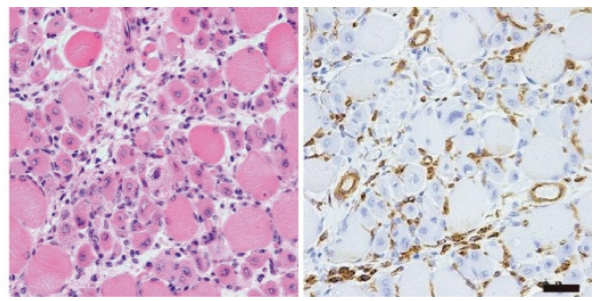

Figure $\mathbf{5}$ Lectin staining. Representative tissue sections obtained from ischemic hind limbs stained with H\&E and lectin. Scale bar $=40 \mu \mathrm{m}$.

\section{Discussion}

We demonstrated that the effect of diabetes on RAGE expression can be imaged and quantified in a murine femoral artery ligation model of limb ischemia using a RAGEtargeting ${ }^{99 \mathrm{~m}}$ Tc-labeled probe and SPECT/CT imaging. The quantitative expression of RAGE from the scans correlated with the degree of suppression of angiogenesis measured from lectin staining on immunohistological sections of the ischemic and non-ischemic limbs. We have previously shown that the effect of diabetes to suppress angiogenesis in a similar live animal model can be imaged with ${ }^{99 \mathrm{~m}}$ Tc-HYNIC-RGDs targeting $\alpha v \beta_{3}$ integrin in ischemic limbs of diabetic mice with femoral artery ligation compared to non-diabetic mice [15]. The results of this current study show the potential feasibility of imaging and quantifying in living subjects another important biological signal in the development of peripheral arterial disease.

RAGE is a $35 \mathrm{kDa}$ polypeptide of the immunoglobulin superfamily that is a multiligand receptor shown to play an important role in vascular disease [2-11]. This receptor is constitutively expressed in low levels on smooth muscle cells and endothelial cells in vascular walls [4]. RAGE binds ligands that induce expression and activation of signaling pathways important in promoting inflammation and reducing vascular reactivity. These ligands include advanced glycation endproducts (AGEs), S100/Calgranulin proteins, high-mobility group box 1 protein (HMGB1), and oxidized LDL. Ligand-RAGE binding activates intracellular pathways that generate reactive oxygen species, reduce nitric oxide availability, promote monocyte and leukocyte chemotaxis, and increase cytokine secretion [4-7]. Our finding of higher quantitative uptake of our radiolabeled probe in the contralateral (non-ischemic) limbs of the diabetic compared to the non-diabetic nonischemic limbs supports the ability of this imaging technology to document the effect of diabetes alone to induce RAGE expression in the peripheral arteries.

As occlusive lower extremity lesions progress, flow reserve is lost and there is further progression to resting hypoxia. In the non-diabetic limb, in response to tissue hypoxia, VEGF is released locally via the HIF-1a pathway and stimulates angiogenesis through multiple mechanisms that include increased proliferation and decreased apoptosis of endothelial cells and chemoattraction of monocytes into the ischemic tissue [8,9]. In diabetes, this normally adaptive response to hypoxia is blunted. RAGE has been shown to have a major mechanistic role in this maladaptive response by reducing VEGF mRNA and by inducing a defect in signal transduction of VEGF in monocytes which reduces their response to chemotactic protein-1, resulting in fewer monocytes in the tissue to stimulate angiogenesis $[11,12,17]$. While the murine femoral artery ligation hind limb ischemia model lacks the component of occlusive proximal arterial disease found in humans, it is currently a standard small-animal model used to study the molecular biology of limb ischemia [18]. The results of the experiments reported in this manuscript concur with the molecular biology reported for RAGE and angiogenesis pathways.

Clinical imaging tests for lower extremity ischemia focus on detection of blood flow reduction and/or presence and 
location of occlusive arterial lesions [19]. There is potential for a molecular imaging approach targeting the biology of peripheral artery disease to demonstrate the extent of small-vessel disease. Two important targets in this disease process are RAGE expression and its effect on the angiogenic responses to tissue hypoxia. A pathology study reported by Rigghaler et al. in 1995 documented prominent enhancement of endothelial RAGE expression in small- and medium-sized arteries in patients with occlusive peripheral vascular disease both with and without diabetes [20]. While large vessels such as the aorta can be visualized at necropsy, smaller arteries require multiple sampling for histology and quantification is subject to sampling error. With this limitation, it is more difficult to assess the total extent of receptor expression. An in vivo molecular imaging approach which can visualize an entire limb has the potential to provide generalized vascular expression of RAGE in live subjects both as a research tool and as a non-invasive marker for the effect of therapies directed at suppressing RAGE to improve the symptoms and prognosis for PAD.

Experimental studies suppressing RAGE ligands have shown improvement in angiogenic response to limb ischemia $[13,14]$. Drugs that inhibit ligands that bind RAGE have been tried in humans, but each has limitations regarding efficacy or untoward side effects [21]. Aminoguanidine, a small hydralazine-like compound, blocks AGE formation but did not advance in clinical trials due to adverse side effects in diabetics attributed to sequestration of pyridoxal and vitamin B6 deficiency [21]. Another approach is to block AGEs with soluble RAGE to prevent binding to RAGE and suppress initiation of the signaling pathways [22]. Soluble RAGE made from the extracellular two thirds of the receptor was developed for mouse studies, but limited quantities are currently available. A humanized rat monoclonal antiRAGE antibody that antagonizes RAGE interactions with multiple ligands was shown to be a potent protector against the toxic effects of sepsis [23]. Because of the multiple ligands binding RAGE and its importance in a spectrum of diseases, there is a clear impetus to developing better RAGE-suppressing drugs. A non-invasive tool that can quantify RAGE expression in vivo would be useful in monitoring the effects of such drug on the molecular signals.

\section{Conclusions}

The results of these experiments document the feasibility of imaging and quantifying RAGE expression in the hind limbs of a relevant mouse model of limb ischemia and show the effect of diabetes to increase the expression and thereby reduce angiogenesis. Future directions include combined imaging protocols targeting both RAGE and either $\alpha v \beta_{3}$ integrin and/or VEGF to more completely map the biology of limb ischemia in the live animal, to follow the mice longer after occlusion, and to monitor the functional consequences of flow reduction using ultrasound techniques.

\section{Abbreviations}

AGEs: Advanced glycation endproducts; DTPA: Diethylene triamine pentaacetic acid; FOV: Field of view; HIF-1a: Hypoxia-inducible factor-1 alpha; HMGB1: High-mobility group box 1; ID: Injected dose; PAD: Peripheral artery disease; RAGE: Receptor for advanced glycation endproducts; SPECT/CT: Single-photon emission computed tomography/computed tomography; STZ: Streptozotocin; VEGF: Vascular endothelial growth factor.

\section{Competing interests}

The authors declare that they have no competing interests.

\section{Authors' contributions}

$Y T$ helped design the experiments, prepared the tracers, and performed the experiments. MK helped in the acquisition of data. $\amalg$ helped design the experiments, analyze and interpret data, and prepare the manuscript. GZ performed the tissue staining. AMS helped in the design of the experiments and as consultant. CL helped with the animal experiments and with the anesthesia, injections, imaging, necropsy, and tissue preparation. All authors read and approved the final manuscript.

\section{Acknowledgments}

This work was supported in part by RO1HL089874 (NHLBI).

\section{Author details}

${ }^{1}$ Department of Medicine, Columbia University Medical Center, 622 West 168th St, PH 10 room 203, New York, NY 10032, USA. ²Department of Pathology, Columbia University Medical Center, New York, NY 10032, USA.

${ }^{3}$ Department of Medicine, New York University Medical Center, New York, NY 10016, USA.

Received: 2 January 2013 Accepted: 20 April 2013 Published: 11 May 2013

\section{References}

1. Harja E, Bu D-X, Hudson BI, Chang JS, Shen X, Hallam K, Kalea AZ, Lu Y, Rosario RH, Oruganti S, Nikolla Z, Belov D, Lalla E, Ramasamy R, Yan SF, Schmidt AM: Vascular and inflammatory stresses mediate atherosclerosis via RAGE and its ligands in apoE ${ }^{-/-}$mice. J Clin Invest 2008, 118:183-194.

2. Zhong Y, Li SH, Liu SM, Szmitko PE, He XQ, Fedak PW, Verma S: C-reactive protein upregulates receptor for advanced glycation end products expression in human endothelial cells. Hypertension 2006, 48:504-511.

3. Ramasamy R, Yan SF, Herold K, Clynes R, Schmidt AM: Receptor for advanced glycation end products fundamental roles in the inflammatory response: winding the way to the pathogenesis of endothelial dysfunction and atherosclerosis. Ann NY Acad Sci. 2008, 1126:7-13.

4. Sena CM, Matafome P, Crisóstomo, Rodrigues L, Fernandes R, Pereira P, Seica RM: Methylglysoxal promotes oxidative stress and endothelial dysfunction. Pharmacol Res 2012, 65:497-506.

5. Yao D, Brownlee M: Hyperglycemia-induced reactive oxygen species increase expression of the receptor for advanced glycation end products (RAGE) and RAGE ligands. Diabetes 2010, 59:249-255.

6. Ehlermann P, Eggers K, Bierhaus A, Most P, Weichenhan D, Greten J, Nawroth PP, Katus HA, Remppis A: Increased proinflammatory endothelial response to SI00A8/A9 after preactivation through advanced glycation end products. Cardiovasc Diabetol 2006, 5:6.

7. Wautier $\mathrm{J}$, Guillausseau PJ: Advanced glycation end products, their receptors and diabetic angiopathy. Diabetes Metab 2001, 27:535-542.

8. Tammela T, Enholm B, Alitalo K, Paavonen K: The biology of vascular endothelial growth factors. Cardiovasc Res 2004:12-002.

9. Babiak A, Schumm AM, Wangler C, Loukas M, Wu J, Dombrowski S, Matuschek C, Kotzerke J, Dehio C, Waltenberger J: Coordinated activation of VEGFR-1 and VEGFR-2 is a potent arteriogenic stimulus leading to enhancement of regional perfusion. Cardiovasc Res 2004, 61:789-795. 
10. Waltenberger J: VEGF resistance as a molecular basis to explain the angiogenesis paradox in diabetes mellitus. Biochem Soc Trans 2009, 37:1167-1170.

11. Carr CL, Qi Y, Davidson B, Chadderdon S, Jayaweera AR, Belcik JT, Benner C, Xie A, Lindner JR: Dysregulated selectin expression and monocyte recruitment during ischemia-related vascular remodeling in diabetes mellitus. Arterioscler thromb Vas Biol. 2011, 31:2526-2533.

12. Shoji T, Koyama H, Morioka T, Tanaka S, Kizu A, Motoyama K, Mori K, Fukumoto S, Shioi A, Shimogaito N, Takeuchi M, Yamamoto Y, Yonekura H, Yamamoto H, Nishizawa Y: Receptor for advanced glycation end products is involved in impaired angiogenic response in diabetes. Diabetes 2006, $55: 2245-2255$.

13. Tamarat R, Silvestre J-S, Huijberts M, Benessiano J, Ebrahimian TG, Duriez M, Wautier M-P, Wautier JL, Levy B-I: Blockade of advanced glycation endproduct formation restores ischemia-induced angiogenesis in diabetic mice. PNAS 2003, 100:14.

14. Goova MT, Li J, Kislinger T, Qu W, Lu Y, Bucciarelli LG, Nowygrod S, Wolf BM, Caliste X, Yan SF, Stern DM, Schmidt AM: Blockade of receptor for advanced glycation end-products restores effective wound healing in diabetic mice. Am J Pathol 2001, 159:513-525.

15. Tekabe Y, Shen X, Li Q, Luma J, Weisenberger D, Schmidt AM, Yan SF, Haubner R, Johnson LL: Imaging the effect of RAGE on angiogenic response to hindlimb ischemia in diabetes. EJNMMI Res 2011, 1(1):3. PMCID: PMC3192466.

16. Tekabe Y, Luma J, Einstein AJ, Sedlar M, Qing L, Schmidt AM, Johnson LL: A novel monoclonal antibody for RAGE-directed imaging identifies accelerated atherosclerosis in diabetes. J Nucl Med 2010, 51:92-97.

17. Mori RD, Straino S, Carlo AD, Mangoni A, Pompili G, Palumbo R, Bianchi ME, Capogrossi MC, Germani A: Multiple effects of high mobility group box protein 1 in skeletal muscle regeneration. Arterioscler Thromb Vasc Biol 2007, 27:2377-2383.

18. Couffinhal T, Silver M, Zheng LP, Kearney M, Witzenbichler B, Isner J: Mouse model of angiogenesis. Am J Pathol 1998, 152:1667-1679.

19. Chan D, Anderson ME, Dolmatch BL: Imaging evaluation of lower extremity infrainguinal disease: role of the noninvasive vascular laboratory, computed tomography angiography, and magnetic resonance angiography. Tech Vasc Interventional Rad. 2009, 13:11-22.

20. Ritthaler U, Deng Y, Zhang Y, Greten J, Abel M, Sido B, Allenberg J, Otto G, Roth H, Bierhaus A, Ziegler R, Schmidt AM, Waldherr R, Wahl P, Stern DM, Nawroth PP: Expression of receptors for advanced glycation end products in peripheral occlusive vascular disease. Am J Pathol 1995, 146:688-694.

21. Reddy PV, Beyaz A: Inhibitor of the Maillard reaction and AGE breakers as therapeutics for multiple diseases. Drug Discov Today 2006, 11:13-14.

22. Park L, Raman KG, Lee KJ, Yan L, Ferran L, Chow WS, Stern D, Schmidt AM: Suppression of accelerated diabetic atherosclerosis by the soluble receptor for advanced glycation endproducts. Nat Med 1998, 4:1025-1031.

23. Finlay WJ, Cunningham O, Lambet MA, Darmanin-Sheehan A, Liu X, Fennell BJ, Mahon CM, Cummins E, Wad JM, O'Sullivan CM, Yang T, Piche N, Pittman DD, Paulsen J, Tchistiakova L, Kodangattil S, Gill D, Hufton SE: Affinity maturation of humanized rat antibody for anti-RAGE therapy: comprehensive mutagenesis reveals a high level of mutational plasticity both inside and outside the complementarity-determining regions. $J \mathrm{Mol}$ Biol 2009, 388:541-558.

\section{Submit your manuscript to a SpringerOpen ${ }^{\odot}$ journal and benefit from:}

- Convenient online submission

- Rigorous peer review

- Immediate publication on acceptance

- Open access: articles freely available online

- High visibility within the field

- Retaining the copyright to your article

Submit your next manuscript at $\gg$ springeropen.com 